\title{
MANIFESTATIONS OF LIFEWORLD CRISIS AMONG SYRIAN MALE YOUTH IN JORDANIAN REFUGEE CAMPS
}

\author{
Mohammed Abdel Karim Al-Hourani, Abdel Baset Azzam, and Rania Jaber
}

\begin{abstract}
This study explores manifestations of lifeworld crisis among a sample of 362 Syrian refugee male youth in the Za'atari camp in Jordan. It fills a gap in research about the conditions of Syrian refugees in the camps. The findings reveal that the first-rank manifestation of the crisis was psychological stress: participants reported feeling fearful, distrustful, absent-minded, threatened, and worried, and having difficulty falling asleep. Second, the youth suffered a lack of gratification with regard to food, money, comfortable accommodation, water for drinking and cleaning, health care, and clothes. Third, they had a loss of meaning in their lives, including loss of interest in surrounding events, of hope about the future, of motivation to do things, of quality of life, of friendships, and of freedom. Fourth, they suffered from anomie, which implies loss of respect for moral rules, rights, and regulations, and the loss of physical security, social stability, and human dignity. Coping strategies used by participants to overcome these circumstances included religiosity, belief in returning home, accepting the situation as representing God's will, regarding the camp as the best alternative, and controlling their feelings.
\end{abstract}

Keywords: youth refugee, refugee crisis, Syrian refugees, Jordan

Mohammed Abdel Karim Al-Hourani PhD (the corresponding author) is an Associate Professor of Applied Sociological Theory in the Sociology Department at the University of Sharjah, P.O. Box 27272, Sharjah, UAE. Email: malhourani@sharjah.ac.ae. Professor Al-Hourani can also be reached at Yarmouk University, Irbid, Jordan. Email: mhorani@yu.edu.jo

Abdel Baset Azzam PhD is an Assistant Professor of Political Sociology at Yarmouk University, Irbid, Jordan. Email: Abdazzam72@yahoo.com

Rania Jaber $\mathrm{PhD}$ is an Assistant Professor of Development in the Sociology Department, University of Jordan, Amman 11942, Jordan. Email: Rania.jaber@ju.edu.jo 
International Journal of Child, Youth and Family Studies (2019) 10(4.1): 3-23

In "Syria's displaced: A photo essay", Nina Berman (2016) described the early days of the camp to which many Syrian refugees were sent when they arrived in neighboring Jordan:

In late July 2012, the first Syrian families arrived at the Za'atari refugee camp, a barren strip of land twelve kilometers from the Syrian border and seventy kilometers from the Jordanian capital, Amman. At the time, Andrew Harber, UNHCR's Country Representative in Jordan said, "We are the first to admit that it is a hot desolate location. Nobody wants to put a family who has already suffered so much in a tent in the desert, but we have no choice." (p. 102)

Living conditions in the camp are harsh. Not only do the refugees lack a home, a nation, and citizenship, but they also lack "proper social power, proper voice, proper face" (Soguk, 1999, p. 243). The lifeworld (shared daily experience) of the camp doesn't meet the fundamental needs of Syrian refugee youth and allows few possibilities for solving their problems. Hence, the term "crisis" is used to draw attention to the fact that the camp is a multidimensional existential problem in itself: The problems of youth refugees arise not only in meeting physical needs like shelter and food, but also in meeting social, cultural, and psychological needs.

\section{Literature Review}

The Syrian refugee crisis has been described as one of the worst since World War II (Amnesty International, 2015). However, there is limited literature on this crisis (Yazgan, Utku, \& Sirkeci, 2015), and especially on youth in the refugee camps, as complicated procedures are required to access participants and collect data. For this reason, most studies have focused on the situation of non-camp refugees and the cultural, social, and economic context of the host societies and policy responses. Furthermore, the impact of Syrian refugees on the host societies has received much attention, as have the challenges that Syrian refugees are facing in the host society (Abu Tarboush, 2014; Al-Hourani, 2017; Smeran \& Smeran, 2014; Yazgan et al., 2015).

After wars and other traumatic events, refugees in affected regions, including Syrian refugees, have suffered threats to security and life, death of family members and friends, anxiety, disruption of education, depression, deprivation, exploitation, economic suffering, hunger, exile, and displacement (Beiser, 1999; Egeland, 2015; Farwell, 2001; Liebkind, 1996). Furthermore, research on refugees in the camps has revealed that they have suffered from lack of freedom while feeling resentment, restlessness, and doubt about their self-worth; these feelings charged those restricted refugees with hostility and aggressiveness (Abdi, 2008; Crisp, 2000; George, 2010). Young refugees, whether in a camp or not, face social, cultural, and academic adjustments that are often exacerbated by racism, conflicting cultural values, educational gaps, language difficulties, culture shock, health problems, poverty, isolation, and symptoms of post-traumatic stress disorder (PTSD) arising from war, violence, or loss of family members (Ngo \& Schleifer, 2005). 
Psychological stress is one of the most important dimensions of the crisis in the refugee camps. When refugees arrive at the camps, they encounter problems that can cause such stress, including the lack of accommodation, of basic necessities like clean water, and of employment (Ghumman, McCord, \& Chang, 2016). Studies conducted on Syrian refugees in the Za'atari camp in Jordan revealed that they were suffering from symptoms of psychological distress including anger, fearfulness, nervousness, difficulty falling asleep or staying asleep, hopelessness about the future, and spells of terror and panic (Basheti, Qunaibi, \& Malas, 2015). Furthermore, Syrian refugees in the camp suffered from mental disorders, depression, social isolation, feelings of insecurity, worries about children, lack of fulfilment of basic needs, and unemployment (Al Adyleh \& Al Zghoul, 2017; Momani \& Al-Fraihat, 2016).

Reese Masterson, Usta, Gupta, and Ettinger (2014) conducted a cross-sectional survey of Syrian refugee women in Lebanon and found that, in relation to mental health, more than $75 \%$ of the women reported having all seven stress-related symptoms covered in the survey: feeling constantly tense, being sick or tired, feeling worried or concerned, being irritable or in a bad mood, suffering from loss of sleep or sleep disorders, having reduced ability to complete normal tasks, and beating or taking anger out on children. The study also showed that women who experienced violence had statistically significantly higher mean stress scores; however, only $9.2 \%$ of them received psychological support and mental health services (Reese Masterson et al., 2014).

An assessment report of Syrian refugee youth in the Za'atari camp conducted jointly by the Norwegian Refugee Council (NRC) and $\mathrm{REACH}^{1}$ (2016) revealed that, although youth in the oldest age bracket ( 25 to 32 years) commented on formal education as being important, their level of interest tended to be the lowest. Male youth often reported feeling an expectation and responsibility to provide for and support their families through seeking gainful employment (NRC \& Reach, 2016).

In Mrayan's (2016) study, Syrian refugee females referred to their lives at the Za'atari camp as "living in the Stone Age" - primitive and surrounded with hardships. Faced with the absence of male protection and support, and with the responsibility of providing for their families, the females had to abandon their sheltered lives and look for ways to survive. By "making do to get by", as many participants referred to their coping strategy, they came to lead a life they would never have thought possible before the war (Mrayan, 2016).

Researchers have found that many refugees demonstrate an ability to cope with circumstances. In Mrayan's 2016 study, religious faith was one of the central coping mechanisms reported by refugees as helping them achieve a sense of purpose, meaning, and control. Other research on refugees' coping strategies has also indicated that the use of religion and spirituality

\footnotetext{
${ }^{1}$ Renewed Efforts Against Child Hunger and undernutrition (https://www.reachpartnership.org/it/home).
} 
International Journal of Child, Youth and Family Studies (2019) 10(4.1): 3-23

is very common among this group (Goodman, 2004; Khawaja, White, Schweitzer, \& Greenslade, 2008).

Moreover, Syrians living inside the Za'atari camp moved their tents in order to live in closer proximity to their families, friends, and extended communities; they thereby maintained elements of their customary social networks and social structures (Sultani, 2012). As well, they sustained a network of social support by maintaining various paths of communication with the outside world and with each other: broadcast media, mobile phone contact with their relatives in Syria, and face-to-face and mobile phone contact with other Syrian refugees (Sultani, 2012).

The growing body of research on Syrian refugees has generally focused on scattered dimensions of the refugee problem in the camps: education, violence, unemployment, family separation, and so on (Alpaydin, 2017; Cassity \& Gow, 2005; Lee, 1988; Marlow, 2010). The term "crisis" seems to be fruitful since it gathers these dimensions under one comprehensive concept.

Both policy and research increasingly recommend focused investigation on the impacts of refugee camps on youth (Cooper, 2007). This follows from the fact that youth may be particularly vulnerable to physical and psychosocial risks, including military and paramilitary recruitment, sexual abuse, delinquency, and depression (Crisp, 2003; Harrell-Bond, 2000; Norwegian Refugee Council, Redd Barna, \& UNHCR, 1999).

International non-governmental organizations working in the Za'atari camp have reported that Syrian refugee youth face challenges such as disrupted education and emotional growth, and limited livelihood development and earning opportunities. In 2016, REACH, a joint initiative dedicated to informing more effective humanitarian action, stated:

It is against this challenging backdrop that humanitarian actors are working to enhance youth well-being and meet psychosocial needs, by providing youth with opportunities to complete their education, develop necessary technical and life skills, and actively participate in their communities (p. 2).

At present, we know very little about the circumstances of Syrian refugee youth in the Za'atari camp and lack the literature necessary to inform the work of humanitarian actors in the refugee camps in Jordan. We therefore undertook this study in order to fill this gap and to focus specifically on male youth since Syrian culture, historically, has attached the meaning of productive power in all domains of life to male youth, and it is regarded as shameful for a young man to be unemployed or dependent on his family This feeling of shame could be expected to exacerbate the stresses on male refugees. Furthermore, few studies have focused on male youth in Syrian refugee camps. It is the intention of this study to help fill the gap and expand the scope of the literature on Syrian male youth refugees. We note also that another study in this issue, "Sexual Harassment of Syrian Female Youth in Jordanian Refugee Camps", helps us to understand the experiences of females in the camps. 
International Journal of Child, Youth and Family Studies (2019) 10(4.1): 3-23

The main goal of this study is to explore both the circumstances (the difficulties and challenges) that embody the manifestations of the lifeworld crisis that Syrian male youth suffer while living in the camp, and the coping mechanisms used for overcoming these circumstances. Thus, this study addresses two main questions: (a) What are the manifestations of lifeworld crises for males in the camp and how do Syrian refugee male youth rank them? and (b) What coping mechanisms are used by Syrian refugee male youth to overcome the difficulties and challenges of living in the camp?

\section{The Za'atari Syrian Refugee Camp in Jordan}

The Za'atari camp was established in July of 2012. As described by Mrayan (2016), it stretched over two miles and was located in the northern part of Jordan in the Mafraq Desert. Due to its proximity to the Za'atari village, a small town in the Mafraq Governorate, the camp came to be known as the Za'atari camp ... and became the most concentrated site for Syrian refugees in Jordan... The camp was initially designed to house 5,000 refugees. However, after one year of establishment it was housing more than 30,000 refugees. Within two years, it had become the world's second largest refugee camp and the largest in the region with over 100,000 refugees. As of today, the camp has become Jordan's fourth largest city. It has six hospitals, three schools, eight mosques, [and] a number of public facilities. (UNHCR, 2015)

A report issued by REACH (2017) stated that "As of February 2017, 656,170 Syrian refugees were registered in Jordan. According to UNHCR, 79,737 or 15\% of them are registered in the Za'atari camp." This represented a slight increase from the previous year when REACH (2016) reported that:

655,833 Syrian refugees have registered with UNHCR in Jordan. Among them, $56.9 \%$ are under the age of 18 . Approximately $20 \%$ of Syrian refugees in Jordan have settled in the refugee camps of Al Zaatari in Mafraq governorate, and of Azraq in Zarqa. Three quarters of these camp populations are below the age of 35. (p. 2)

Approximately 36,000 refugees were school-aged children in 2013; however, only $22 \%$ of them were actually enrolled in school (Education Sector Working Group, 2013). According to Schmidt (2013), the reasons children did not attend school included harassment and violence while traveling to and from school and during school; abuse and corporal punishment from teachers; a desire to remain with family; needing to work to support the family; travel distance; and inadequate toilet facilities.

Ledwith (2014) found there was little formal employment available within the camp. Thus, refugees monetized what they had - possessions, supplied aid, labor, and even their own bodies. Child labor was common. Some refugees, including experienced merchants and electricians, could 
International Journal of Child, Youth and Family Studies (2019) 10(4.1): 3-23

start successful business enterprises, though many of the commercial activities were questionable, or actually illegal. According to Ledwith, crime was a problem in Za'atari. Even though it had become safe enough for aid workers to live in the camp with the refugees, many forms of crime still existed. Smuggling, theft, violence, sexual- and gender-based violence, and armed-forces recruiting had all been observed (Ledwith, 2014).

Mrayan (2016) reported that refugees' expectations affected their experience during resettlement. Because of Jordan's reputation as a refugee haven, Syrian refugees came with high hopes. Upon encountering the camp's lack of preparedness during the first year, these gave way to growing bitterness and resentment, and increasing hostility towards aid workers, camp officials, and camp properties, as well as each other (Mrayan, 2016).

\section{Understanding the Refugee Camp as a Crisis}

This study was inspired by Habermas' (1973) legitimation crisis theory with its focus on the kinds of social crises that are anchored in an absence of the administrative capabilities and resources needed to maintain legitimate structure and order. This is often regarded as a normative theory - one that concerns what ought to be in general. However, several authors, including Grant (2007), Leydesdorff (1996), and Seidl and Becker(2006), have pointed out that although Habermas' theory includes applicable issues such as anomie, alienation, and solidarity, this applicability was neglected. In fact, we found that manifestations of the crisis addressed by Habermas (see Figure 1) correspond closely to the immediate and pressing problems facing refugees in the camp. In previous studies about refugees (e.g., Al Adyleh \& Al Zghoul, 2017; Momani \& Al-Fraihat, 2016), each manifestation was measured separately. These studies showed that Syrian refugees in the camp were suffering mental disorders, depression, social isolation, feelings of insecurity, worries about children, lack of fulfilment of basic needs, and unemployment. But what distinguishes Habermas' theory is the gathering of these manifestations of crisis — which are experienced as personal problems — in a comprehensive framework, which includes tracing complex interconnections between reproduction processes (those that maintain the social pattern) and structural components to analyze the emergence of crisis.

The social and cultural contexts in which people produce and reproduce their identities is very important for generating the meaning of their lives. There is no doubt that living in the camp excludes people from these contexts in which they experienced the institutionalization of their identity, and this situation represents an existential crisis for all who live in the camp.

According to Habermas, "Only when members of a society experience structural alterations as critical for continued existence and feel their social identity threatened can we speak of crisis" (Habermas, 1973, p. 3). At the same time, when we speak of crisis we speak of lifeworld crisis, since lifeworld for Habermas is "the milieu where actors are taking part in interactions through which they develop, confirm, and renew their membership in social groups and their own identities" (Habermas, 1987, p. 139). 
In his analysis of the crisis, Habermas (1987) gave a central signficance to the expression "the requisite quantity" when evaluating whether a crisis point has been reached. The phrase "refers to the extent, quality, and temporal dimension of the respective system performances (value, administrative decision, legitimation, and meaning)" (Habermas, 1973, p. 49). From this perspective the crisis is a consequence of the fundamental needs that the respective system cannot satisfy:

The economic system does not produce the requisite quantity of consumable values; or, the administrative system does not produce the requisite quantity of rational decisions; or, the legitimation system does not provide the requisite quantity of generalized motivations; or, the sociocultural system does not generate the requisite quantity of action-motivating meaning (Habermas, 1973, p. 49).

In his theory of communicative action, Habermas (1987) expanded his analysis of legitimation crisis to formulate more generalized manifestations of crisis. He suggested three reproduction processes with complex interconnections in three domains of structural components of the lifeworld (see Figure 1). Thus, disturbances of cultural reproduction manifest in a loss of meaning and lead to corresponding legitimation and orientation crises. Disturbances of social integration manifest themselves in social anomie and corresponding conflicts. In such cases it would be difficult to meet the need for coordination that arises with new situations from the inventory of legitimate orders. Disturbances in the socialization process manifest in psychopathologies and corresponding phenomena of alienation (Habermas, 1987, pp. 140-141).

\begin{tabular}{|c|c|c|c|c|}
\hline \multirow{2}{*}{$\begin{array}{l}\text { Domain of } \\
\text { disruption }\end{array}$} & \multicolumn{3}{|c|}{ Structural components } & \multirow{2}{*}{$\begin{array}{l}\text { Dimension of } \\
\text { evaluation }\end{array}$} \\
\hline & Culture & Society & Person & \\
\hline $\begin{array}{l}\text { Cultural } \\
\text { reproduction }\end{array}$ & $\begin{array}{l}\text { Loss of } \\
\text { meaning }\end{array}$ & $\begin{array}{l}\text { Withdrawal of } \\
\text { legitimation }\end{array}$ & $\begin{array}{l}\text { Crisis in } \\
\text { orientation and } \\
\text { education }\end{array}$ & $\begin{array}{c}\text { Rationality of } \\
\text { knowledge }\end{array}$ \\
\hline $\begin{array}{l}\text { Social } \\
\text { integration }\end{array}$ & $\begin{array}{l}\text { Unsettling of } \\
\text { collective identity }\end{array}$ & Anomie & Alienation & $\begin{array}{l}\text { Solidarity of } \\
\text { members }\end{array}$ \\
\hline Socialization & $\begin{array}{c}\text { Rupture of } \\
\text { tradition }\end{array}$ & $\begin{array}{l}\text { Withdrawal of } \\
\text { motivation }\end{array}$ & Psychopathologies & $\begin{array}{l}\text { Personal } \\
\text { responsibility }\end{array}$ \\
\hline
\end{tabular}

Figure 1. Manifestations of crisis when reproduction processes are disrupted. Adapted from The theory of communicative action (Vol. 2; Figure 22, p. 143) by J. Habermas, 1987, Boston, MA: Beacon. 
International Journal of Child, Youth and Family Studies (2019) 10(4.1): 3-23

Four manifestations of the crisis were derived from Habermas' (1987) theory in order to develop the instrument used in this study (see Appendix A):

1. Loss of meaning. This manifestation is measured by disturbances that prevent "continuity of tradition and coherence of knowledge sufficient for daily practice". Such disturbances include multiple losses: interest in surrounding events, hope about the future, motivation to do things, quality of life, friendships, and freedom.

2. Psychological distress. This is manifested in tensions that threaten psychological security, such as feeling permanently fearful, distrustful, absent-minded, threatened, and worried, and having difficulty falling asleep.

3. Anomie. This is manifested in loss of respect for moral rules, rights, and regulations, and loss of physical security, social stability, and human dignity.

4. Lack of gratification. This is measured by lack of food, money, clothes, comfortable accommodation, health care, and water for drinking and cleaning.

The lifeworld of the refugee camps emerged accidentally as a problematic time-space of living for the refugees who had suddenly lost everything they had built (Turner, 2015). Therefore, in addition to the manifestations listed above, we investigated the coping mechanisms that represent the reactions and responses of refugee youth toward their situation. These are manifested in beliefs and behaviors that reduce the stresses and tensions of the crisis, such as beliefs regarding fate and God's will, acceptance of the status quo, helping others, prayers, hiding feelings, and convincing oneself that living in the camp is the best available option.

\section{Method}

\section{Participants}

A volunteer sample of 362 Syrian male refugee youth, aged 18 to 32 years, agreed to participate in this study; all were living in the Za' atari camp. Participants were recruited by visiting the tents of refugee families, and by using the relationships among the youth to extend the sample. Sociocultural considerations led to the decision to limit the sample to males. The structure of the Syrian family is still a patriarchal one, in which males are the holders of authority, and usually the primary income-earners of the household. The shame that male refugees feel at being unemployed increases the impact on them of lifeworld crisis in the camp.

\section{Instrument}

The lifeworld crisis questionnaire consists of 32 items representing four dimensions of crisis and one dimension of coping mechanisms. Each item is measured on a 4-point scale, ranging from 1 (not at all) to 4 (to a large degree). Dimensions of the scale were: Anomie (A), Loss of Meaning (LM), Psychological Stress (PS), Lack of Gratification (G), and Coping Strategies (CS). 
To assure the content validity of the scale, 15 specialists judged the suitability of each item in measuring the dimension to which it belongs. The scale has discriminant validity; correlation coefficients between items and the subscales to which they belong were significant $(p<.001)$.

With regard to reliability, the scale has excellent internal consistency (Cronbach's alpha = .92) for the four dimensions of crisis. The total scores of Cronbach's alpha for the subscales were: $\mathrm{A}=.93 ; \mathrm{LM}=.86 ; \mathrm{PS}=.87 ; \mathrm{G}=.87$. For the coping strategies, Cronbach's alpha was about .70 .

\section{Results}

Descriptive statistics (see Table 1) reveal that the majority $(201 ; 55.5 \%$ ) of the Syrian refugee male youth in the sample were more than 25 years old. From a Syrian cultural perspective, they were of an age for employment, productivity, responsibility, and family support. Hence, it may be expected that male youth in the camp are particularly vulnerable to psychological stress.

Table 1. Research Variables

\begin{tabular}{|c|c|c|}
\hline Category & $n$ & Percent \\
\hline \multicolumn{3}{|l|}{ Age } \\
\hline Less than 25 years & 161 & 44.5 \\
\hline More than 25 years & 201 & 55.5 \\
\hline \multicolumn{3}{|c|}{ Years of living in the camp } \\
\hline 1-3 years & 93 & 25.7 \\
\hline 4-7 years & 269 & 74.3 \\
\hline \multicolumn{3}{|l|}{ Educational attainment } \\
\hline No education & 30 & 8.3 \\
\hline Elementary & 84 & 23.2 \\
\hline Basic & 159 & 43.9 \\
\hline Secondary & 58 & 16.0 \\
\hline Higher education & 31 & 8.6 \\
\hline \multicolumn{3}{|l|}{ Currently studying } \\
\hline No & 309 & 85.4 \\
\hline Yes & 53 & 14.6 \\
\hline Currently working & 188 & 51.9 \\
\hline No & 174 & 48.1 \\
\hline \multicolumn{3}{|l|}{ Yes } \\
\hline \multicolumn{3}{|c|}{ All family members live in the camp } \\
\hline No & 89 & 24.6 \\
\hline Yes & 273 & 75.4 \\
\hline \multicolumn{3}{|c|}{ Loss of family members during the war } \\
\hline No & 232 & 64.1 \\
\hline Yes & 130 & 35.9 \\
\hline \multicolumn{3}{|c|}{ Number of family members in the camp } \\
\hline 3 or fewer & 47 & 13.0 \\
\hline 4-6 & 156 & 43.1 \\
\hline 7-9 & 125 & 34.5 \\
\hline 10 or more & 34 & 9.4 \\
\hline Total & 362 & 100.0 \\
\hline
\end{tabular}


International Journal of Child, Youth and Family Studies (2019) 10(4.1): 3-23

The majority of youth in our sample (74.3\%) had lived between 4 and 7 years in the camp, and thus had ample experience of living in the camp and had been affected by the hard conditions. Furthermore, although the majority had basic education (43.9\%), the vast majority (85.4\%) did not continue their education in the camp. In a youth assessment reported by REACH (2016), male youth in the camp indicated that they preferred gainful employment in order to support their families (p. 4). Still, $48.1 \%$ were unemployed, which would presumably intensify their feelings of psychological stress, especially since the majority $(75.4 \%)$ were living with their entire family in the camp. The fact that almost half (43.1\%) were living with 4 to 6 family members, and $34.5 \%$ were living with 7 to 9 family members, indicates that the youth bear a heavy burden of responsibility.

Table 2. Means and Standard Deviations of Lifeworld Crisis Manifestations

\begin{tabular}{lcclc}
\hline Manifestation & $M$ & $S D$ & Degree & Rank \\
\hline Psychological stress & 2.87 & .862 & Medium & 1 \\
Lack of gratification & 2.72 & .756 & Medium & 2 \\
Loss of meaning & 2.59 & .921 & Medium & 3 \\
Anomie & 2.52 & .984 & Medium & 4 \\
Total score (1-4) & 2.68 & .668 & Medium & \\
\hline
\end{tabular}

Descriptive statistics (see Table 2) indicate that the total score from the 4-point scale used for the manifestations of lifeworld crisis in the camp is significant $(M=2.68, S D=0.668)$. This confirms that Syrian refugee male youth in the Za'atari camp are indeed suffering from the four dimensions or manifestations, and we are justified in speaking about the living conditions in the camp as a crisis. For the subscales of the crisis, psychological stress ranked first $(M=2.87, S D=$ 0.862). This indicates that they were fearful, distrustful, absent-minded, feeling threatened, having difficulty falling asleep, and worried, a result consistent with other research (Basheti et al., 2015; Ghumman et al., 2016).

The second-ranking manifestation of the lifeworld crisis is lack of gratification $(M=2.72$, $S D=0.756$, which is shown by lack of food, money, comfortable accommodation, water for drinking and cleaning, health care, and clothes (Al Adyleh \& Al Zghoul, 2017; Momani \& AlFraihat, 2016). Loss of meaning is the third-ranked $(M=2.59, S D=0.921)$ manifestation of the crisis. This dimension represents loss of many things: interest in surrounding events, hope about the future, motivation to do things, valued living, friendships, and freedom (Crisp, 2000; Egeland, 2015). Fourth-ranked $(M=2.52, S D=0.984)$ is anomie: the loss of respected moral rules, protection, obvious order, human dignity, and respected rights and prohibitions (Abdi, 2008; George, 2010). 
International Journal of Child, Youth and Family Studies (2019) 10(4.1): 3-23

Table 3. Correlations between Research Variables and Lifeworld Crisis Manifestations

\begin{tabular}{|c|c|c|c|c|}
\hline Variable & $\begin{array}{l}\text { Loss of } \\
\text { meaning }\end{array}$ & $\begin{array}{l}\text { Psychological } \\
\text { stress }\end{array}$ & Anomie & $\begin{array}{l}\text { Lack of } \\
\text { gratification }\end{array}$ \\
\hline \multicolumn{5}{|l|}{ Age } \\
\hline Pearson correlation & .022 & .001 & .015 & -.045 \\
\hline Sig. (2-tailed) & 678 & .985 & .773 & .396 \\
\hline \multicolumn{5}{|c|}{ Years of living in the camp } \\
\hline Pearson correlation & $-.201 * *$ & $-.133 *$ & $-.324 * *$ & .052 \\
\hline Sig. (2-tailed) & .000 & .011 & .000 & .322 \\
\hline \multicolumn{5}{|l|}{ Educational attainment } \\
\hline Pearson correlation & $-.168 * *$ & $-.281 * *$ & $-.152 * *$ & $-.291 * *$ \\
\hline Sig. (2-tailed) & .001 & .000 & .004 & .000 \\
\hline \multicolumn{5}{|l|}{ Currently studying } \\
\hline Pearson correlation & -.024 & -.062 & -.019 & .003 \\
\hline Sig. (2-tailed) & .643 & .237 & .719 & .954 \\
\hline \multicolumn{5}{|l|}{ Currently working } \\
\hline Pearson correlation & .039 & .001 & .018 & .024 \\
\hline Sig. (2-tailed) & .463 & .982 & .731 & .650 \\
\hline \multicolumn{5}{|c|}{ All family members live in the camp } \\
\hline Pearson correlation & .090 & .049 & .059 & $.123^{*}$ \\
\hline Sig. (2-tailed) & .086 & .353 & .260 & .019 \\
\hline \multicolumn{5}{|c|}{ Loss of family members during the war } \\
\hline Pearson correlation & .071 & .048 & -.056 & .015 \\
\hline Sig. (2-tailed) & .177 & .361 & .287 & .770 \\
\hline \multicolumn{5}{|c|}{$\begin{array}{l}\text { Number of family members in the } \\
\text { camp }\end{array}$} \\
\hline Pearson correlation & .003 & .047 & -.044 & .040 \\
\hline Sig. (2-tailed) & .955 & .375 & .407 & .448 \\
\hline
\end{tabular}

Note: $\mathrm{N}=362$

* Correlation is significant at the 0.05 level (2-tailed)

** Correlation is significant at the 0.01 level (2-tailed)

Results revealed several correlations between research variables and the dimensions of the lifeworld crisis in the camp (see Table 3). The more years the youth had spent living in the camp, the lower were their assessments of loss of meaning, psychological stress, and anomie. The higher their educational attainment, the lower their assessments of the four dimensions of the lifeworld crisis in the camp. Moreover, length of camp residency and living with all family members correlated with higher assessments by the youth of their lack of gratification.

Table 4. Means and Standard Deviations of Coping Mechanisms

\begin{tabular}{lcccc}
\hline Coping mechanism & M & SD & Degree & Rank \\
\hline Praying hard for a good ending to the situation & 3.96 & 0.186 & High & 1 \\
Retaining the belief that I would return home & 3.56 & 0.765 & High & 2 \\
$\begin{array}{l}\text { Accepting the situation because it embodies God's } \\
\text { will }\end{array}$ & 3.49 & 0.891 & High & 3 \\
Helping other refugees in the camp & 3.45 & 0.758 & High & 4 \\
$\begin{array}{l}\text { Convincing myself that the camp is currently the } \\
\text { best alternative for us }\end{array}$ & 3.26 & 0.890 & High & 5 \\
Doing my best to control and hide my feelings & 2.93 & 1.030 & Medium & 6
\end{tabular}


International Journal of Child, Youth and Family Studies (2019) 10(4.1): 3-23

Coping mechanisms (Total)

3.44

0.508

High

As shown in Table 4, the coping mechanism the Syrian youth used most was "Praying hard for a good ending to the situation" $(M=3.96, S D=0.186)$. In the second rank was "Retaining the belief that I would return home" $(M=3.56, S D=0.765)$. The third most-used mechanism was "Accepting the situation because it embodies God's will" $(M=3.49, S D=0.891)$. Thus, consistent with Mrayan's 2016 study, our results indicate that religious faith played a major role in building resilience among Syrian refugee male youth in the Za'atari camp. The fourth mechanism used was, "Helping other refugees in the camp" $(M=3.45, S D=0.758)$. The fifth mechanism was "Convincing myself that the camp is currently the best alternative for us" $(M=3.26, S D=0.890)$. Although these five coping mechanisms were ranked preferentially, they were all estimated highly $(M=3.44, S D=0.508)$ by the Syrian refugee male youth, indicating that they used these mechanisms frequently in building their resilience. The lowest-ranked coping mechanism was "Doing my best to control and hide my feelings" $(M=2.93, S D=1.030)$.

Table 5 shows that there were several correlations between the research variables and the coping mechanisms. Older participants, gave a higher ranking to helping other refugees and convincing oneself that the camp is the best current alternative. More years of living in the camp correlate with higher rankings for accepting the situation as an expression of God's will. Moreover, the more the participants were studying, the lower they ranked helping other refugees, convincing oneself that the camp is currently the best alternative, and doing their best to control and hide their feelings.

\section{Discussion}

The findings show that Syrian refugee male youth were undergoing lifeworld crises in the Za'atari camp: the four manifestations of crisis measured in this study are integrated and interrelated in the lifeworlds of those in the camp. Although participants ranked the four manifestations hierarchically, the results of this study direct attention to the camp as a crisis in itself and the four dimensions as a holistic crisis that violates and threatens identity, human dignity, freedom, and existential security.

The longer youth remain in the camp, the less humanity and dignity they feel. Although they are engaged in helping other refugees, and see living in the camp as a manifestation of God's will, they recognize that living in the camp is not consistent with human dignity. Believing in God's will does not mean that they are satisfied about their situstion as a whole. The findings of this study are consistent with other studies in the field (Al Adyleh \& Al Zghoul, 2017; Beiser, 1999; Egeland, 2015; Farwell, 2001; Liebkind, 1996; Momani \& Al-Fraihat, 2016). 
International Journal of Child, Youth and Family Studies (2019) 10(4.1): 3-23

Table 5. Pearson Correlation Coefficients between Research Variables and Coping Mechanisms

\begin{tabular}{|c|c|c|c|c|c|c|c|}
\hline Variable & $\begin{array}{c}\text { Praying } \\
\text { hard }\end{array}$ & $\begin{array}{l}\text { Will return } \\
\text { home }\end{array}$ & $\begin{array}{c}\text { Accepting the } \\
\text { situation }\end{array}$ & $\begin{array}{l}\text { Helping other } \\
\text { refugees }\end{array}$ & $\begin{array}{c}\text { Camp is the } \\
\text { best alternative }\end{array}$ & $\begin{array}{l}\text { Controlling } \\
\text { and hiding } \\
\text { feelings }\end{array}$ & $\begin{array}{c}\text { Coping } \\
\text { mechanisms }\end{array}$ \\
\hline \multicolumn{8}{|l|}{ Age } \\
\hline Pearson correlation & .096 & .045 & .057 & $.128 *$ & $.158 * *$ & -.001 & $.111^{*}$ \\
\hline Sig. (2-tailed) & .068 & .388 & .279 & .014 & .003 & .990 & .034 \\
\hline \multicolumn{8}{|c|}{ Years of living in the camp } \\
\hline Pearson correlation & -.012 & $.215 * *$ & -.009 & .016 & .024 & $.262 * *$ & $.159 * *$ \\
\hline Sig. (2-tailed) & .827 & .000 & .862 & .767 & .646 & .000 & .002 \\
\hline \multicolumn{8}{|l|}{ Educational attainment } \\
\hline Pearson correlation & .074 & $-.125 *$ & -.020 & -.029 & -.087 & $-.161 * *$ & $-.124 *$ \\
\hline Sig. (2-tailed) & .160 & .018 & .709 & .582 & .100 & .002 & .019 \\
\hline \multicolumn{8}{|l|}{ Currently studying } \\
\hline Pearson correlation & .038 & -.042 & -.057 & $-.143 * *$ & $-.140 * *$ & $-.154 * *$ & $-.153 * *$ \\
\hline Sig. (2-tailed) & .472 & .427 & .279 & .006 & .008 & .003 & .004 \\
\hline \multicolumn{8}{|l|}{ Currently working } \\
\hline Pearson correlation & .097 & .040 & .036 & $.129 *$ & .083 & .054 & .101 \\
\hline Sig. (2-tailed) & .067 & .450 & .501 & .014 & .115 & .307 & .055 \\
\hline \multicolumn{8}{|c|}{ All family members in the camp } \\
\hline Pearson correlation & .097 & $.110^{*}$ & .056 & .026 & .060 & .061 & .097 \\
\hline Sig. (2-tailed) & .066 & .036 & .288 & .621 & .252 & .244 & .065 \\
\hline \multicolumn{8}{|c|}{ Loss of family members during the war } \\
\hline Pearson correlation & -.072 & .076 & -.057 & -.080 & -.040 & .022 & -.020 \\
\hline Sig. (2-tailed) & .171 & .147 & .281 & .128 & .452 & .673 & .700 \\
\hline \multicolumn{8}{|c|}{$\begin{array}{l}\text { Number of family members in the } \\
\text { camp }\end{array}$} \\
\hline Pearson correlation & .058 & .071 & -.067 & -.025 & .010 & $.104 *$ & .039 \\
\hline Sig. (2-tailed) & .271 & .177 & .201 & .632 & .849 & .048 & .457 \\
\hline
\end{tabular}

Note: $N=362$

* Correlation is significant at the 0.05 level (2-tailed)

$* *$ Correlation is significant at the 0.01 level (2-tailed) 
Although psychological stress was assessed as being at the first rank of the crisis, it is also a reflection of the other dimensions of the crisis. In the camp, participants encountered many existential problems capable of causing the symptoms of psychological stress that they experienced. Its manifestations included anger, fearfulness, nervousness, difficulty falling or staying asleep, hopelessness about the future, and spells of terror or panic (Basheti et al., 2015).

The longer the youth had been living in the camp, the lower their rankings of the dimensions of the lifeworld crisis, except that the ranking for lack of gratification remained high especially when family members were also in the camp. This could indicate that they were to some extent adapted to the conditions of the camp, but that prolonged lack of gratification was still a stressor for them, especially when they saw that their family members were suffering and struggling to achieve their basic needs. The majority of Syrian youth in the Za'atari camp were from the Dara'a governorate, just across Jordan's nearby northern border with Syria. This proximity to home, together with their previous familiarity with Jordan, mitigated their stress to some extent. Furthermore, the majority of the youth had cell phones and were able to maintain contact with their families, relatives, and other refugees outside the camp. These contacts were very important as they provided the youth with networks of social and psychological support (Sultani, 2012).

The results indicate religious faith was at the first rank as a coping mechanism for the Syrian male youth in the Za'atari camp. Using religiosity and spirituality to cope is very common among refugees everywhere (Goodman, 2004; Khawaja et al., 2008; Mrayan, 2016). The Syrian youth refugees are all Muslims; therefore, the precepts of Islam are at the core of their culture and everyday life. This culture is religious and fatalistic, so it is not surprising that prayers would be the first-ranked coping mechanism. Furthermore, the Syrian male youth participants believed that their stay in the camp would be temporary and they would ultimately return to their homes. This belief worked as a coping mechanism, even though returning home was not immediately possible.

The older the Syrian male youth and the higher their educational attainment, the higher they tended to rank the coping mechanisms of helping other refugees and of convincing themselves that the camp was the best alternative for them. It could be that older and more educated male youth are more likely than others to think logically and rationally. They know that they cannot return to Syria because of the war and the hard living experienced by other refugees who have returned; at the same time, they have no other place to go and therefore cannot leave the camp. Helping each other, making friends of acquaintances, and accepting the status quo thus served to minimize tensions and suffering (Sultani, 2012).

Furthermore, the longer youth live in the camp, the more they become aware of the complexities of the situation and the fact that it is not in their power to bring about a change in their circumstances. In this problematic situation, the coping mechanism adopted by our participants was to attribute being in the camp to God's will. This type of thinking is deeply rooted 
International Journal of Child, Youth and Family Studies (2019) 10(4.1): 3-23

in Islamic culture: people learn to accept hardships and events beyond their control by regarding them as determined by fate.

\section{Conclusion}

For Syrian youth, life in a refugee camp includes the manifestations of crisis noted above: loss of meaning, psychological distress, anomie, and lack of gratification. This means that living in a camp is not an appropriate solution for refugees and violates human rights and dignity. Moreover, living in a camp constrains young people's energy and productivity because refugee camps don't include facilities and empowerment for youth to be productive. Although the crisis of living will not be eliminated completely as long as youth stay at the camp, supporting and empowering them will reduce the impact of the crisis, and should be regarded as an interim solution for the situation of these youth.

In future research on Syrian refugee youth, there is a need to focus on female youth and compare their situation with that of their male counterparts. Furthermore, the research sample should be collected from all refugee camps in Jordan, not just the Za'atari camp. In addition, research should compare the manifestations of crisis among youth in camps and those outside camps.

The research findings suggest several recommendations for authorities and practitioners working with Syrian youth in refugee camps. First, these youth should be involved in training workshops that enable them to engage in productive projects. Second, camp authorities should exert more effort to control the camp and enforce order and security. Third, in the light of the

findings of this study, practitioners and authorities should bear in mind that youth in the camp should be supported with regard to basic needs and facilities that reflect human rights, such as sufficient food, water, clothes, and playgrounds. Furthermore, youth should be empowered to continue their education through being involved in programs that can provide ongoing educational support. 
International Journal of Child, Youth and Family Studies (2019) 10(4.1): 3-23

\section{References}

Abdi, A. M. (2008). In limbo: Dependency, insecurity, and identity amongst Somali refugees in Dadaab Camps. Bildhaan, 5(1), 17-34.

Abu Tarboush, R. (2014). The social and psychological effects of the Syrian crisis on Syrian refugee children in Jordan (Unpublished master's thesis). University of Jordan, Amman, Jordan.

Al Adyleh, L., \& Al Zghoul, A. (2017, May). The problems of Syrian refugees in Al Za'atari Camp-Jordan. Paper presented at the second international Refugees in the Middle East conference, Amman, Jordan.

Al-Hourani, M. (2017). The burdens of Syrian refugees and the revitalization of Jordanian national identity prerogatives: An analytical descriptive approach from the perspective of cultural trauma. Journal of Social Sciences-Kuwait, 45(3), 294-331.

Alpaydin, Y. (2017). An analysis of educational policies for school-aged Syrian refugees in Turkey. Journal of Education and Training Studies, 5(9), 36-44. doi:10.11114/jets.v5i9.2476

Amnesty International. (2015). The global refugee crisis: A conspiracy of neglect [POL 40/1796/2915]. Retrieved from http://www.amnestyusa.org/sites/default/files/p4575_global_refugee_crisis_syria.pdf

Basheti, I. A., Qunaibi, E. A., \& Malas, R. (2015). Psychological impact of life as refugees: A pilot study on a Syrian camp in Jordan. Tropical Journal of Pharmaceutical Research, 14, 16951701.

Beiser, M. (1999). Strangers at the gate: The 'Boat People's' first ten years in Canada. Toronto, ON: University of Toronto Press.

Berman, N. (2016). Syria's displaced: A photo essay. Dissent, 63(3), 102-113. doi:10.1353/dss.2016.0044

Cassity, E. A., \& Gow, G. (2005). Making up for lost time: The experiences of Southern Sudanese young refugees in high schools. Youth Studies Australia, 24(3), 51-55.

Cooper, E. (2007). Praxis in a refugee camp? Meanings of participation and empowerment for long-term refugee youth. Children, Youth and Environments 17(3), 104-121.

Crisp, J. (2000). A state of insecurity: The political economy of violence in Kenya's refugee camps. African Affairs, 99, 601-632. doi:10.1093/afraf/99.397.601 
International Journal of Child, Youth and Family Studies (2019) 10(4.1): 3-23

Crisp, J. (2003). No solutions in sight: The problem of protracted refugee situations in Africa [Working paper no. 75]. New Issues in Refugee Research, 12. Geneva, Switzerland: Evaluation and Policy Analysis Unit, UNHCR.

Education Sector Working Group. (2013). Joint education needs assessment: Za'atari refugee camp - Jordan: April 2013. Retrieved from http://data.unhcr.org/syrianrefugees/download.php?id=2347

Egeland, J. (2015). A way out of the Syrian carnage. Brown Journal of World Affairs, 22(1), 297304.

Farwell, N. (2001). 'Onward through strength': Coping and psychological support among refugee youth returning to Eritrea from Sudan. Journal of Refugee Studies, 14(1), 43-69. doi:10.1093/jrs/14.1.43

George, M. (2010). A theoretical understanding of refugee trauma. Clinical Social Work Journal, 38, 379-387. doi:10.1007/s10615-009-0252-y

Ghumman, U., McCord, C., \& Chang, J. (2016). Posttraumatic stress disorder in Syrian refugees: A review. Canadian Psychology, 57(4), 246-253.

Goodman, J. H. (2004). Coping with trauma and hardship among unaccompanied refugee youths from Sudan. Qualitative Health Research, 14(9), 1177-1196. doi:10.1177/1049732304265923

Grant, C. B. (2007). Uncertainty and communication: New theoretical investigations. Hampshire, UK: Palgrave Macmillan.

Habermas, J. (1973). Legitimation crisis. Boston, MA: Beacon.

Habermas, J. (1987). The theory of communicative action (Vol.2). Boston, MA: Beacon.

Harrell-Bond, B. (2000). Are refugee camps good for children? [Working paper no. 29]. New Issues in Refugee Research. Geneva, Switzerland: Evaluation and Policy Analysis Unit, UNHCR.

Khawaja, N. G., White, K. M., Schweitzer, R., \& Greenslade, J. (2008). Difficulties and coping strategies of Sudanese refugees: A qualitative approach. Transcultural Psychiatry, 45(3), 489-512. doi:10.1177/1363461508094678

Ledwith, A. (2014). Zaatari: The instant city. Boston, MA: Affordable Housing Institute.

Lee, E. (1988). Cultural factors in working with Southeast Asian refugee adolescents. Journal of Adolescents, 11, 167-179. doi:10.1016/S0140-1971(88)80051-4 
International Journal of Child, Youth and Family Studies (2019) 10(4.1): 3-23

Leydesdorff, L. (1996). Luhmann's sociological theory: Its operationalization and future perspectives. Social Science Information, 35, 283-306. doi:10.2139/ssrn.2229106

Liebkind, K. (1996). Acculturation and stress: Vietnamese refugees in Finland. Journal of Crosscultural Psychology, 27, 161-180. doi:10.1177/0022022196272002

Marlow, J. M. (2010). Beyond the discourse of trauma: Shifting the focus on Sudanese refugees. Journal of Refugee Studies, 23(20), 183-198. doi:10.1093/jrs/feq013

Momani, F. A., \& Al-Fraihat, E. J.. (2016). The predictability of some social and demographic factors in the occurrence of psychosomatic disorder among Syrian refugees. Jordan Journal of Social Sciences, 9(3), 305-321.

Mrayan, S. (2016). Female refugees' resilience and coping mechanisms at the Za'atari CampJordan (Doctoral dissertation, LLc. no. 10240845). Retrieved from https://pqdtopen.proquest.com/doc/1861209061.html?FMT=ABS

Ngo, H., \& Schleifer, B. (2005). Immigrant children and youth in focus. Canadian Issues, Spring, 29-33.

Norwegian Refugee Council, Redd Barna (Save the Children Norway), \& the UN High Commissioner for Refugees (UNHCR). (1999). Conference Report: Protection of Children and Adolescents in Complex Emergencies. Oslo, Norway: Authors. Retrieved from https://www.unhcr.org/3ae690200.pdf

Norwegian Refugee Council \& REACH. (2016). Youth assessment: Zaatari and Azraq camps, Jordan [Report]. Retrieved from https://www.nrc.no/globalassets/pdf/reports/youthassessment-zaatari-and-azraq-camps/youth-assessment-zaatari-and-azraq-camps-jordan.pdf

REACH. (2017). WASH infrastructure \& services assessment in Zaatari camp, Jordan. Retrieved from https://data2.unhcr.org/en/documents/download/60880

Reese Masterson, A., Usta, J., Gupta, J., \& Ettinger, A. S. (2014). Assessment of reproductive health and violence against women among displaced Syrians in Lebanon. BMC Women's Health, 14(25). doi:10.1186/1472-6874-14-25

Schmidt, C. (2013, June 20). Education in the second largest refugee camp in the world [Web log post]. Global Partnership for Education. Retrieved from http://www.globalpartnership.org/blog/education-second-largest-refugee-camp-world

Seidl, D., \& Becker, K. H. (2006). Organizations as distinction generating and processing systems: Niklas Luhmann's contribution to organization studies. Organization, 13(1), 9-35. doi:10.1177/1350508406059635 
International Journal of Child, Youth and Family Studies (2019) 10(4.1): 3-23

Smeran, A., \& Smeran, M. (June,2014). The impact of Syrian refugees on Jordan. Paper presented at the Conference of Humanitarian Relief Between Islam \& International Law, Al Al-Bayt University, Mafraq, Jordan.

Soguk, N. (1999). States and strangers: Refugees and displacements of statecraft. Minneapolis, $\mathrm{MN}$ : University of Minnesota Press.

Sultani, G. (2012). The case of Syrian refugees in the Za'atari refugee camp, Jordan [Field study report]. York, UK: Post-War Reconstruction \& Development Unit, University of York.

Turner, S. (2015). What is a refugee camp? Explorations of the limits and effects of the camp. Journal of Refugee Studies, 29(2), 139-148. doi:10.1093/jrs/fev024

Yazgan, P., Utku, D. E., \& Sirkeci, I. (2015). Editorial: Syrian crisis and migration. Migration Letters, 12(3), 181-192. 


\section{Appendix A}

\section{Questionnaire}

1. Age

2. Years of living in the camp

3. Educational attainment

4. Are you currently studying?

5. Are you currently working?

6. Do all your family members live in the camp?

7. Did you lose any of your family members in the war in Syria?

8. Number of family members in the camp

\section{Loss of meaning}

1. I do not give attention to the events around me in the camp and outside the camp

2. I do not have ambitions regarding my future

3. I do not have motivation to do anything inside the camp

4. I feel depressed about the quality of life in the camp

5. I do not have motivation to make new friendships in the camp

6. Nothing is worth living for in the camp

\section{Psychological distress}

1. I feel fearful permanently

2. I always feel distrust of everything around me

3. I feel continuously absent-minded

4. I have difficulty falling asleep

5. I feel worried about my family members in the camp

6. I feel that I am threatened in the camp

\section{Anomie}

1. There is a lack of respected moral rules in the camp

2. There is no protection from crime in the camp

3. There is no obvious order in the camp

4. Living in the camp causes a loss of human dignity

5. Nothing ensures people's rights in the camp

6. Normally prohibited behaviors become legitimized in the camp

\section{Gratification}

1. There is not enough food available for my family members

2. We do not have enough money to cover our basic needs

3. The tents provided are not appropriate for human living

4. The tents do not protect us from cold in winter and heat in summer

5. Residents in the camp lack health care services

6. We face difficulties in obtaining drinking water

7. There is not enough water for cleaning and personal hygiene

8. We do not have enough appropriate clothes for winter and summer 
International Journal of Child, Youth and Family Studies (2019) 10(4.1): 3-23

\section{Coping mechanisms}

1. Praying hard for a good ending to the situation

2. Retaining the belief that I will return home

3. Accepting the situation because it embodies God's will

4. Helping other refugees in the camp

5. Convincing myself that the camp is currently the best alternative for us

6. Doing my best to control and hide my feelings 